\title{
The effect of host social system on parasite population genetic structure: comparative population genetics of two ectoparasitic mites and their bat hosts
}

\author{
Jaap van Schaik ${ }^{1 *}$, Gerald Kerth ${ }^{2}$, Nadia Bruyndonckx ${ }^{3}$ and Philippe Christe ${ }^{3}$
}

\begin{abstract}
Background: The population genetic structure of a parasite, and consequently its ability to adapt to a given host, is strongly linked to its own life history as well as the life history of its host. While the effects of parasite life history on their population genetic structure have received some attention, the effect of host social system has remained largely unstudied. In this study, we investigated the population genetic structure of two closely related parasitic mite species (Spinturnix myoti and Spinturnix bechsteini) with very similar life histories. Their respective hosts, the greater mouse-eared bat (Myotis myotis) and the Bechstein's bat (Myotis bechsteinii) have social systems that differ in several substantial features, such as group size, mating system and dispersal patterns.
\end{abstract}

Results: We found that the two mite species have strongly differing population genetic structures. In S. myoti we found high levels of genetic diversity and very little pairwise differentiation, whereas in S. bechsteini we observed much less diversity, strongly differentiated populations and strong temporal turnover. These differences are likely to be the result of the differences in genetic drift and dispersal opportunities afforded to the two parasites by the different social systems of their hosts.

Conclusions: Our results suggest that host social system can strongly influence parasite population structure. As a result, the evolutionary potential of these two parasites with very similar life histories also differs, thereby affecting the risk and evolutionary pressure exerted by each parasite on its host.

Keywords: Coevolution, Host-parasite interaction, Local adaptation, Social system, Myotis myotis, Spinturnix myoti, Myotis bechsteinii, Spinturnix bechsteini

\section{Background}

In the evolutionary arms race between hosts and their parasites, the interacting species may use immunological, physiological and behavioural adaptations $[1,2]$. Hosts commonly use behavioural adaptations to avoid exposure, or actively remove, parasites [3]. In addition behavioural adaptations may also affect parasite population structure, thereby potentially reducing parasite intensity [1], and ultimately their evolutionary potential, classically defined as the ability to incorporate genotypes able to outcompete

\footnotetext{
* Correspondence: jvschaik@orn.mpg.de

'Department of Behavioural Ecology and Evolutionary Genetics, Max Planck Institute for Ornithology, Eberhard-Gwinner-Strasse, 82319 Seewiesen, Germany Full list of author information is available at the end of the article
}

those put forward by the opponent [4]. On the population level, a parasite's genetic structure is closely linked to the life histories of both interacting species [5], as well as to the social system of the host [6]. Specifically, the relative rate of dispersal, and thereby gene flow [6], as well as the relative strength of genetic drift $[7,8]$, are important in determining host-parasite coadaptation dynamics. Therefore, comparisons of population genetic structure across multiple host-parasite pairs where hosts differ in key life-history and/or social system traits, will help elucidate how these factors affect microevolutionary host-parasite dynamics.

Relative dispersal rates of hosts and parasites have been studied in a number of systems. For instance, in the black- 
legged kittiwake and a parasitic tick, parasite populations were found to be much more spatially structured than those of their hosts [9]. This difference was attributed to the fact that parasite dispersal was limited to the breeding season of the hosts, and therefore dispersal of the host outside of this period did not result in concurrent parasite dispersal [9]. In contrast, in a comparison of dispersal rates between two shearwater species and three parasitic lice, parasite gene flow was found to be much higher than that of its host, which was attributed to the transmission of parasites at communal wintering grounds where no host gene flow took place [10]. These examples highlight the fact that relative dispersal is dependent on the intricate interaction between the life histories of both species. In cases where gene flow in host and parasite are comparable, genetic drift can also substantially affect host-parasite coevolutionary dynamics as it can impede adaptation; even in cases where standing genetic variation is abundant in both species [8]. This is especially relevant for parasites of vertebrate hosts, where meta-population dynamics often lead to patchily distributed parasite populations. As a result parasite populations often experience extinction events and strong population bottlenecks eg. [11]. Unfortunately, comparative studies investigating the role of host social system in shaping parasite population genetic structure are rare.

In this study, we investigate the population genetic structure of two ectoparasitic mite species that parasitize two closely related bat hosts with differing social systems. The mite species (Spinturnix myoti and Spinturnix bechsteini) are closely related and have indistinguishable life histories [12,13]. As a result, we expect any differences observed in their microgeographic population genetic structure to be primarily the result of differences in the social system of their hosts, the greater mouse-eared bat (Myotis myotis) and the Bechstein's bat (Myotis bechsteinii).

The two host species share similar life-history traits but show substantial differences in their social systems, which include their social organization, social structure and mating system (Table 1). Both are long-lived, monotocous, non-migratory European vespertilionid bat species that follow the temperate cycle. In summer, they form exclusively female maternity colonies, which however differ between the two species in size, location, stability and degree of philopatry (Table 1). Females from different maternity colonies of $M$. myotis sometimes visit other maternity colonies and occasionally co-localize with maternity colonies of closely related Myotis blythii, whereas females from $M$. bechsteinii maternity colonies do not interact with one another or with other species. Males of M. myotis and M. bechsteinii disperse from their natal colony and are solitary throughout the summer $[14,15]$. In the autumn mating season, male $M$. myotis form temporary harems in August and September where several females roost in direct contact with a male for one or more days. In contrast, $M$. bechsteinii mate at swarming sites where the sexes meet very briefly during the night [16]. In winter both species hibernate at underground sites, but again differ in degree of aggregation and body contact, where $M$. myotis may form large clusters whereas M. bechsteinii roosts solitarily [17]. Finally, the species differ in the distance travelled between summer and winter roosts. M. myotis is considered a regional migrant, easily travelling over $50 \mathrm{~km}$, whereas $M$. bechsteinii is considered sedentary, generally not travelling over $30 \mathrm{~km}$ [18]. Both species have recolonized the current study area since the last glacial maximum. However, for $M$. myotis there is the possibility of admixture as multiple glacial refugia have been identified (Iberia and Italy; [19]), while all $M$. bechsteinii in Central Europe are believed to originate from the Balkan region [20]. Both species are parasitized by ectoparasitic mites of the genus Spinturnix, which typically show strong cospeciation with their bat hosts [21].

Spinturnix wing mites live exclusively on membranes of bats, reproduce sexually, are haematophagous and cannot survive off of their host for more than a few hours [22]. Therefore, while dispersal of Spinturnix mites is extensive within bat maternity colonies, where female bats live in close body contact, little (M. myotis) or no (M. bechsteinii) transmission can occur between different maternity colonies in summer [23]. It is expected that horizontal transmission of mites between colonies occurs during bat mating and hibernation periods. Bat maternity colonies constitute optimal conditions for parasite reproduction, and parasites show a strong preference for female and juvenile hosts [24]. Mite abundance subsequently strongly decreases in autumn and throughout hibernation, and it is supposed that they are not able to reproduce during this time [25]. Mites are believed to impose a substantial cost on their hosts during the maternity period [26]. For example, in M. myotis individuals experienced increased oxygen consumption and weight loss when experimentally infected [27]. Mite prevalence and intensity is much higher in $M$. myotis (intensity per female 12-20; [28]) compared to $M$. bechsteinii (intensity per female $1-10$; [29]). S. bechsteini is strictly host specific. S. myoti is found on $M$. myotis as well as its sister species $M$. blythii (which also has an identical social system; [17]). In choice experiments $S$. myoti shows a clear preference for $M$. myotis and it is presumed that $M$. myotis is the main host species [30]. A previous study of mtDNA sequence data in S. bechsteini found strong spatial differentiation between bat colonies and a high temporal turnover in the haplotypes found per bat colony, suggesting frequent local extinction and recolonisation [23].

By comparing the genetic diversity, gene flow and genetic drift of the selected parasite species, we aim to assess the consequences that the differing social systems 
Table 1 Key differences in social system of the two host species

\begin{tabular}{|c|c|c|c|c|}
\hline & $\begin{array}{l}\text { Greater mouse-eared bat } \\
\text { Myotis myotis }\end{array}$ & $\begin{array}{l}\text { Bechstein's bat } \\
\text { Myotis bechsteinii }\end{array}$ & $\begin{array}{l}\text { Predicted effect on parasite } \\
\text { population genetic structure }\end{array}$ & Reference \\
\hline \multicolumn{5}{|l|}{ Social organization } \\
\hline Colony size & Large (50-2000) & Small (10-50) & Larger colonies lead to less genetic drift & {$[17]$} \\
\hline Female natal philopatry & $\begin{array}{l}\text { High; but occasional exchange } \\
\text { of individuals between colonies }\end{array}$ & $\begin{array}{l}\text { Very high; almost no exchange } \\
\text { of individuals between colonies }\end{array}$ & $\begin{array}{l}\text { Lower philopatry leads to more } \\
\text { parasite transmission }\end{array}$ & {$[31,53]$} \\
\hline Roost fidelity & $\begin{array}{l}\text { High; one site (building/cave) } \\
\text { throughout summer }\end{array}$ & $\begin{array}{l}\text { Very low; frequent roost } \\
\text { switching (tree cavities) and } \\
\text { fission-fusion dynamics }\end{array}$ & $\begin{array}{l}\text { Fission-fusion dynamics may increase } \\
\text { genetic drift because colonies split } \\
\text { into subgroups }\end{array}$ & {$[17,54]$} \\
\hline Hibernation & Free-hanging; solitary or clustered & In crevices (mostly solitary) & $\begin{array}{l}\text { Solitary roosting reduces } \\
\text { parasite transmission }\end{array}$ & {$[17]$} \\
\hline Mating system & $\begin{array}{l}\text { Temporary harems (extensive } \\
\text { contact) and/or swarming } \\
\text { (little contact) }\end{array}$ & Swarming (little contact) & $\begin{array}{l}\text { Temporary harems increase } \\
\text { parasite transmission }\end{array}$ & {$[14,16]$} \\
\hline
\end{tabular}

Overview of the key differences in social system between the greater mouse-eared bat (Myotis myotis) and Bechstein's bat (Myotis bechsteinii), and the expected effects thereof on the population genetic structure of their parasites.

of the hosts have on the evolutionary potential of the parasites. In accordance with Nadler [5], we predict that the larger colony size and increased contact rates among colonies of $M$. myotis will result in a less genetically structured population in $S$. myoti, and allow for substantial gene flow between colonies. In contrast, we expect the mite population of $M$. bechsteinii to be highly sub-structured due to reduced dispersal opportunities and strong genetic drift as a result of the smaller and demographically more isolated host colonies.

\section{Methods}

\section{Previously analysed samples}

To compare host and parasite population genetic structure, we have combined newly generated datasets for both parasites (S. myoti: mtDNA cytb sequence data and 8 nucDNA microsatellites; S. bechsteini: 5 nucDNA microsatellites), with previously generated datasets for one of the mite species (S. bechsteini: mtDNA cytb) and both hosts (mtDNA and nucDNA), supplemented for M. myotis with two additional colonies for this study. An overview of the markers and samples previously analysed is given below as well as in the supplemental materials (Additional file 1).

For M. myotis, four summer maternity colonies had been previously genotyped for ten microsatellites and sequenced for the second hypervariable domain (HVII) of the mtDNA control region [31]. For M. bechsteinii, individuals from ten maternity colonies had been genotyped for eight nucDNA microsatellites as well as two mitochondrial microsatellites [20,32]. For S. bechsteini, mites from thirteen bat maternity colonies had been previously sequenced for a $513 \mathrm{bp}$ fragment of Cytochrome B (cytb; mtDNA) [23].

\section{Sample collection and DNA extraction}

We sampled $S$. myoti in six M. myotis maternity colonies in Switzerland and Northern Italy in August 2004 and
2005 (Figure 1, Table 2a). Colony size estimates were made inside the roost and bats were caught either directly inside the colonies' roosts during the day, or upon emergence from the roost entrance at night. Geographic distances between colonies ranged from 16 to about $200 \mathrm{~km}$, which is comparable to the range $M$. myotis is known to disperse between summer and winter roosts [18]. Twenty mites per bat colony, each originating from a different bat, were used for the genetic analyses.

S. bechsteini samples were collected from $13 \mathrm{M}$. bechsteinii maternity colonies in 2002 and in 2007 in two spatially distant regions $( \pm 200 \mathrm{~km})$ in Germany, Lower Franconia (LF) and Rhineland-Palatinate (RP; Figure 1). As $M$. bechsteinii has not been recorded to disperse over $73 \mathrm{~km} \mathrm{[18]} \mathrm{direct} \mathrm{dispersal} \mathrm{of} \mathrm{either} \mathrm{host} \mathrm{or} \mathrm{parasite}$ between regions is not expected. At the same time, within regions, inter-colony distances are again comparable to the expected dispersal distance between summer and winter roosts. We divided the available 18 sampling events from 13 colonies into three main subgroups based on spatial and temporal characteristics (LF in 2002: 100 mites from 5 bat colonies; LF in 2007: 195 mites from 8 bat colonies; RP in 2007: 107 mites from 5 bat colonies). The number of sampling events in each subgroup is less than were analysed for mtDNA [23] as all events with less than 10 samples were discarded in order to ensure sufficient sample sizes for all nucDNA analyses. Samples from 2002 were only used for the temporal analysis, whereas all other comparisons were performed using only the samples from 2007. In all cases, all bats within a (bat-box) roost were caught and sampled for mites, and colony size estimates reflect the number of bats present in the colony. All mites collected from a colony were used for the genetic analysis.

For both mite species, individuals were removed from the bat's wing and tail membrane using soft forceps and stored in $90 \%$ ethanol prior to DNA extraction. Collected 


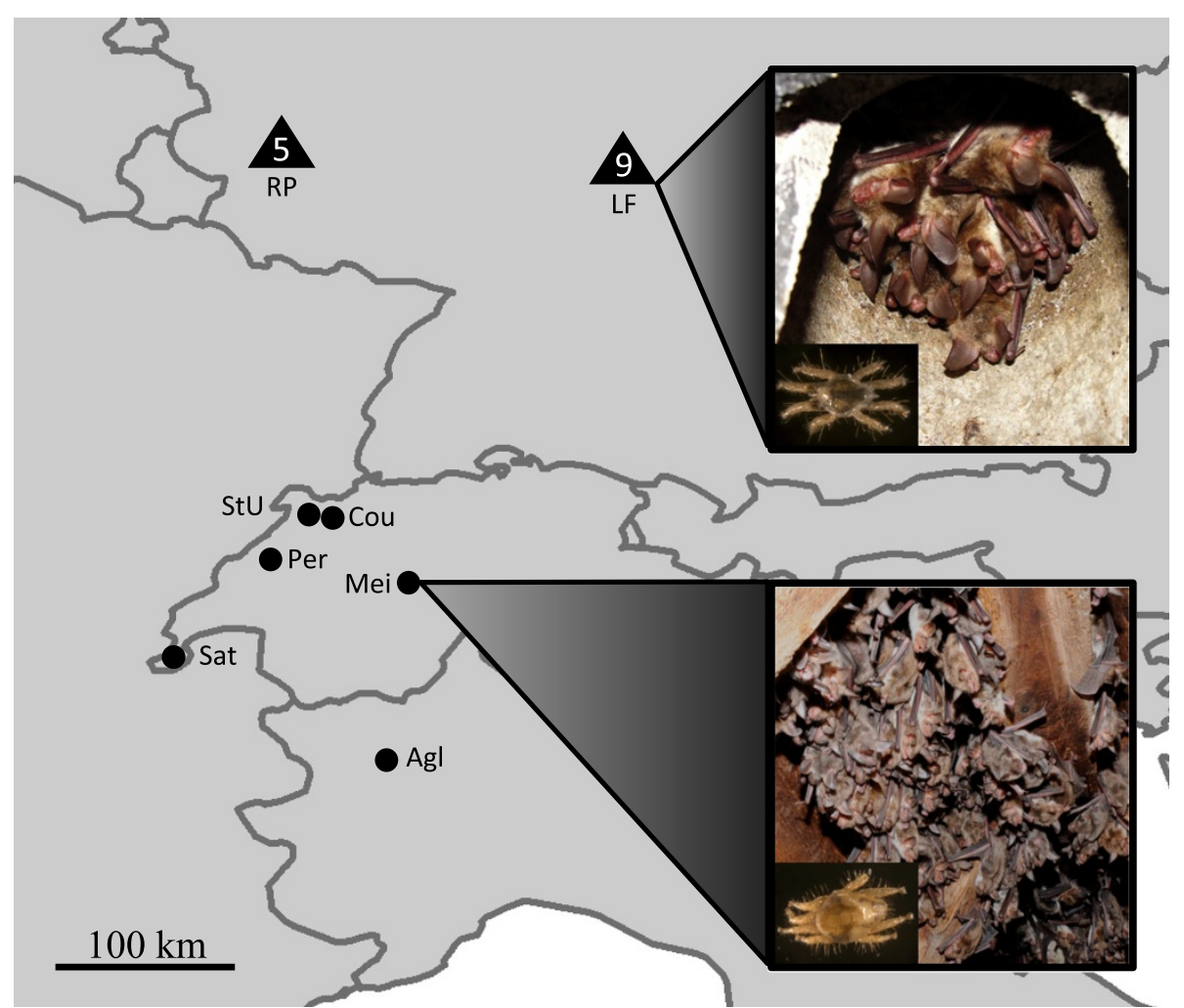

Figure 1 Sampling map. Map of Central Europe showing the sampling locations for Myotis myotis/Spinturnix myoti (circles), and sampling regions for Myotis bechsteinii/Spinturnix bechsteini (triangles). For the latter pairing, the number of sampled colonies within a region is indicated within the triangle because all colonies within a region are located in close proximity to one another. All colony and region names correspond to the abbreviations given in Table 2. For each species, a picture of the typical roosting association is shown with an inset of the studied mite species (picture credits M. bechsteinii: GK, M. myotis: PC, mites: GK \& JvS).

mite specimens were individually rehydrated for two hours in $200 \mu \mathrm{l}$ of sterile water before being crushed in liquid nitrogen. Total DNA was isolated from each individual mite using a standard proteinase K-phenol chloroform method [33].

\section{Additional host samples}

For the two newly analysed M. myotis maternity colonies (Satigny, St-Ursanne), wing tissue punches from 20 bats were obtained with a sterile biopsy punch of the wing membrane $\varnothing 2 \mathrm{~mm}$ [34]. For these colonies samples were taken concurrently with mite samples, for the other bat maternity colonies samples were collected and analysed previously [31]. Samples were preserved, extracted, and sequenced for the second hypervariable domain (HVII) of the mtDNA control region and 10 microsatellites (A13, B11, B22, C113, E24, F19, G9, H19, H29 and G30) as described in Castella et al. [31].

\section{Amplification}

Amplification of Cytochrome b (cytb) for S. myoti was performed according to the protocol described in Bruyndonckx et al. [21] using the primer pair C1-J-2183 and C1-J- 2797mod [35]. Microsatellite loci for both species were developed from an enriched genomic library of S. myoti. For S. myoti, eight microsatellite loci were established (SM7, SM11, SM13, SM17, SM18, SM19, SM51 and SM55), where for $S$. bechsteini only five microsatellites could be successfully amplified (SM11, SM16, SM17, SM18 and SM35) [GenBank: JF288840- JF288850] [36]. Amplification protocol and multiplex configuration were as developed in van Schaik et al. [36].

\section{Mite mtDNA genetic analysis}

Haplotype diversity $(\mathrm{H})$ and nucleotide diversity $(\pi)$ were calculated using ARLEQUIN 3.5 [37]. A statistical parsimony network was computed using TCS 1.21 [38]. An analysis of molecular variance, performed in ARLEQUIN 3.5 , was used to examine the genetic structure and estimate pairwise $\Phi$-statistics among all populations. To test whether $\Phi$-statistics were sensitive to distances between haplotypes, we performed the same analyses based only on haplotypic frequencies. Isolation by distance in mite populations was tested through the correlation between matrices of $\Phi_{\mathrm{ST}} /\left(1-\Phi_{\mathrm{ST}}\right)$ values and log transformed geographic distance using Mantel tests (10,000 permutations) in 
Table 2 Descriptive statistics for all species

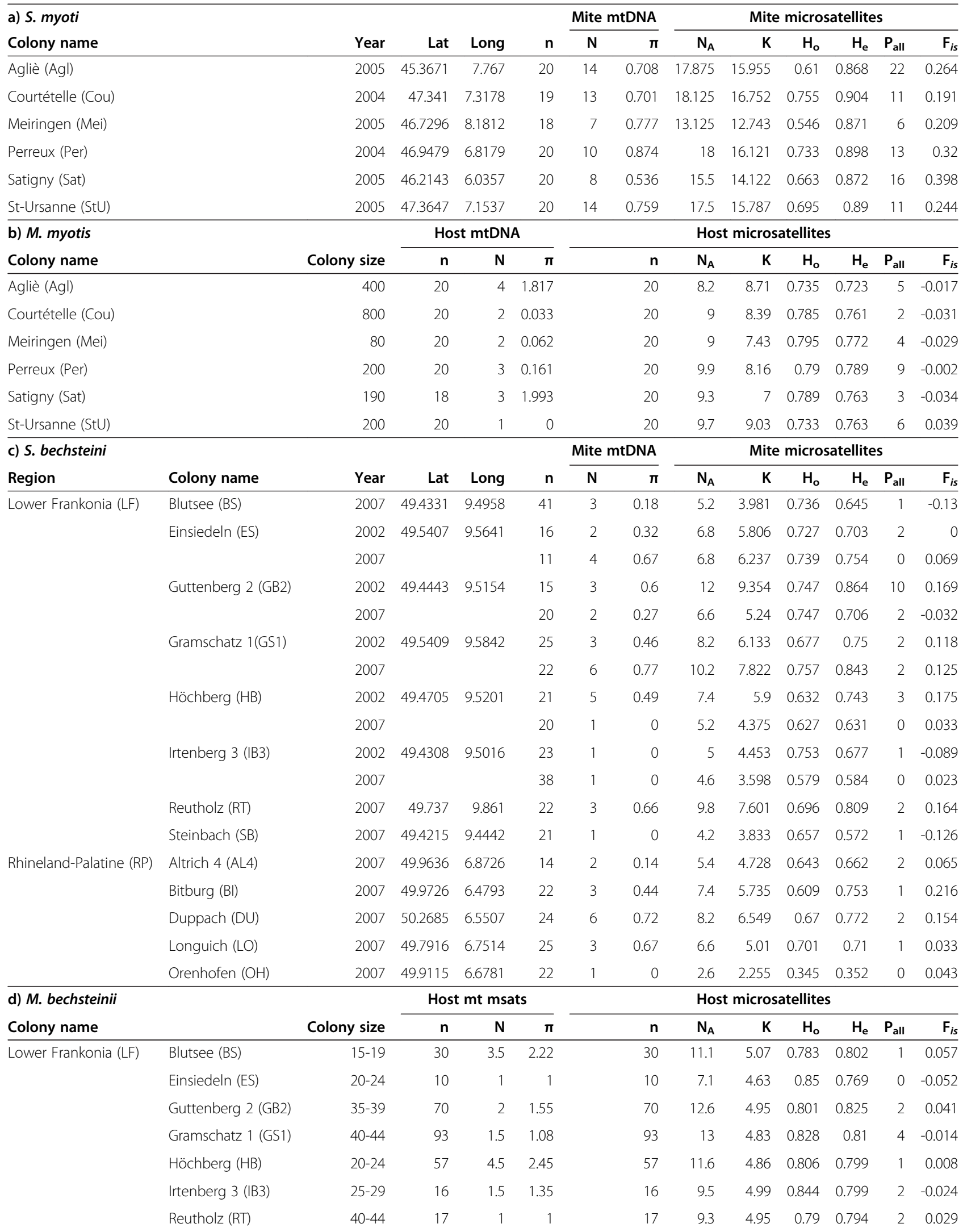


Table 2 Descriptive statistics for all species (Continued)

\begin{tabular}{llrrrrrrrrrrrrr}
\hline & Steinbach (SB) & $20-24$ & 34 & 1 & 1 & & 34 & 9.3 & 4.57 & 0.825 & 0.792 & 1 & -0.007 \\
Rhineland-Palatine (RP) & Bitburg (BI) & $40-44$ & 9 & 1 & 1 & & 9 & 6.8 & 4.85 & 0.819 & 0.795 & 3 & 0.028 \\
& Duppach (DU) & $45-49$ & 20 & 1.5 & & & 1.3 & 9.1 & 4.86 & 0.856 & 0.804 & 1 & -0.039 \\
\hline
\end{tabular}

Description of molecular variability in a) Spinturnix myoti, b) Myotis myotis c) Spinturnix bechsteini d) Myotis bechsteinii. The following parameters are recorded: latitude (Lat), longitude (Long), estimated number of bats in the colony (colony size), number of individuals sequenced/genotyped ( $\mathrm{n}$ ), total number of haplotypes $(N)$, nucleotide diversity $(\pi)$, the mean number of microsatellite alleles per locus $\left(N_{A}\right)$, allelic richness $(K)$, observed $\left(H_{0}\right)$ and expected $\left(H_{e}\right)$ heterozygosities, the number of private alleles per colony $\left(\mathrm{P}_{\mathrm{all}}\right)$, and the inbreeding coefficient $\left(\mathrm{F}_{\mathrm{is}}\right)$. For $\mathrm{S}$. myoti and $\mathrm{S}$. bechsteini the number of individuals sequenced and genotyped was the same for each colony.

FSTAT 2.9.3 [39]. Geographic distances were calculated as the shortest linear distance connecting the populations.

\section{Mite microsatellite genetic analysis}

For both mite species we checked for the presence of null alleles, allelic dropout, and stuttering using MicroChecker 2.2.5 [40]. We also checked for deviations from HardyWeinberg equilibrium and linkage disequilibrium using Genepop on the web 4.0.10 [41]. We calculated number of alleles per locus, allelic richness, observed and expected heterozygosity, $\mathrm{F}_{\mathrm{IS}}$, and pairwise $\mathrm{F}_{\mathrm{ST}}$-values using Fstat 2.9.3 [39]. Number of private alleles was calculated using Genalex 6 [42]. To assess the level of genetic differentiation of mites within and between bat colonies, single-level and hierarchical AMOVAs were performed in Arlequin 3.5 [43]. Isolation by distance was measured by comparing matrices of $\mathrm{F}_{\mathrm{ST}} /\left(1-\mathrm{F}_{\mathrm{ST}}\right)$ and log transformed geographic distance using Mantel tests (10,000 permutations) in FSTAT 2.9.3 [39]. Sequential Bonferroni corrections were used to compute the critical significance levels for simultaneous statistical tests. Pairwise $\mathrm{F}_{\mathrm{ST}}$ and $\mathrm{G}^{\prime \prime} \mathrm{ST}^{-}$-values were calculated using Genodive 2.0b23 [44].

To investigate temporal differentiation of mite populations within a colony, mites from five colonies of $M$. bechsteinii were sampled twice (2002 and 2007) and compared using pairwise $\mathrm{F}_{\mathrm{ST}}$-values and a Mantel test in FSTAT 2.9.3 [39].

\section{Parasite and host comparison}

Summary statistics, diversity indices and population differentiation were calculated for both hosts from existing datasets and the two newly analysed $M$. myotis colonies as described above for mites. To compare parasite and host genetic distances we used a partial Mantel test (10000 permutations) correcting for geographic distance. For comparison of parasite and host mitochondrial genetic distance, we used $\Phi_{\mathrm{ST}} /\left(1-\Phi_{\mathrm{ST}}\right)$, and nuclear genetic distance was compared using $\mathrm{F}_{\mathrm{ST}} /\left(1-\mathrm{F}_{\mathrm{ST}}\right)$ [45]. A structure analysis was performed in STRUCTURE 2.3.3 [46] for all species using only the nucDNA microsatellites, applying an admixture model without location as a prior. For $S$. myoti and $M$. myotis, we selected a range of $\mathrm{K}$ from 1 to 10 , and for S. bechsteini and M. bechsteinii from 1 to 15. Five iterations per $\mathrm{K}$ were run with a burn-in and run length of 200000 and 1000000 repetitions respectively. The most probable $\mathrm{K}$ was inferred using the $\Delta \mathrm{K}$ method of Evanno et al. [47]. Finally, one-tailed Spearman's rank correlation tests were performed using $\mathrm{R}$ [48] to test for a positive correlation between mite diversity indices $(H, \pi$, $\mathrm{K}, \mathrm{H}_{\mathrm{O}}, \mathrm{H}_{\mathrm{E}}$ ) and host colony size.

\section{Results}

\section{M. myotis genetic data}

The additional host mitochondrial analysis revealed that all $H V 2$ haplotypes corresponded to previously published haplotypes [19,31,49] (Table 2b). As expected, M. myotis bat colonies showed high mtDNA differentiation $\left(\Phi_{\mathrm{ST}}=0.56\right.$, $\mathrm{p}<0.001$ ) and, despite being statistically significant, low nucDNA $\left(\mathrm{F}_{\mathrm{ST}}=0.015, \mathrm{p}<0.001\right)$ differentiation, indicating strong female philopatry and male-biased dispersal. Descriptive statistics for all colonies can be found in Table $2 \mathrm{~b}$; results are similar to those previously published by Castella et al. [31].

\section{S. myoti mtDNA}

Among the 117 S. myoti mites sequenced, 49 different $c y t b$ haplotypes were detected. The 697 aligned nucleotides consisted of 49 variables sites, of which 18 were parsimonyinformative. All haplotypes were deposited in GenBank under accession numbers [KJ174107-KJ174155].

The haplotype network of S. myoti presents two star-like patterns with some haplotypes in between (Figure 2a). Two haplotypes were the most represented: h1 was present in $12 \%$ of individuals and h2 in $16.2 \%$. Nine haplotypes were shared between bat colonies and 40 were private haplotypes. The number of haplotypes per population ranged from 7 to 14 (mean $=11$, Table $2 \mathrm{a})$, and nucleotide diversity from 0.536 to 0.874 (mean $=0.726$; Table 2a). S. myoti populations showed low pairwise differentiation (mean $\Phi_{\mathrm{ST}}=0.012$; Table $3 \mathrm{a}$ ), and only Satigny was significantly differentiated from two other populations (Meiringen, Agliè). A mantel test revealed no significant correlation between genetic and geographic distances $\left(\mathrm{r}^{2}=0.02, \mathrm{p}=0.64\right)$.

The 697 bp fragment analysed in S. myoti represents an overlap of $72 \%$ with the 513 bp fragment of $c y t b$ previously analysed for S. bechsteini (Figure 2b; [23]). A comparison of the most common haplotypes of each mite species 


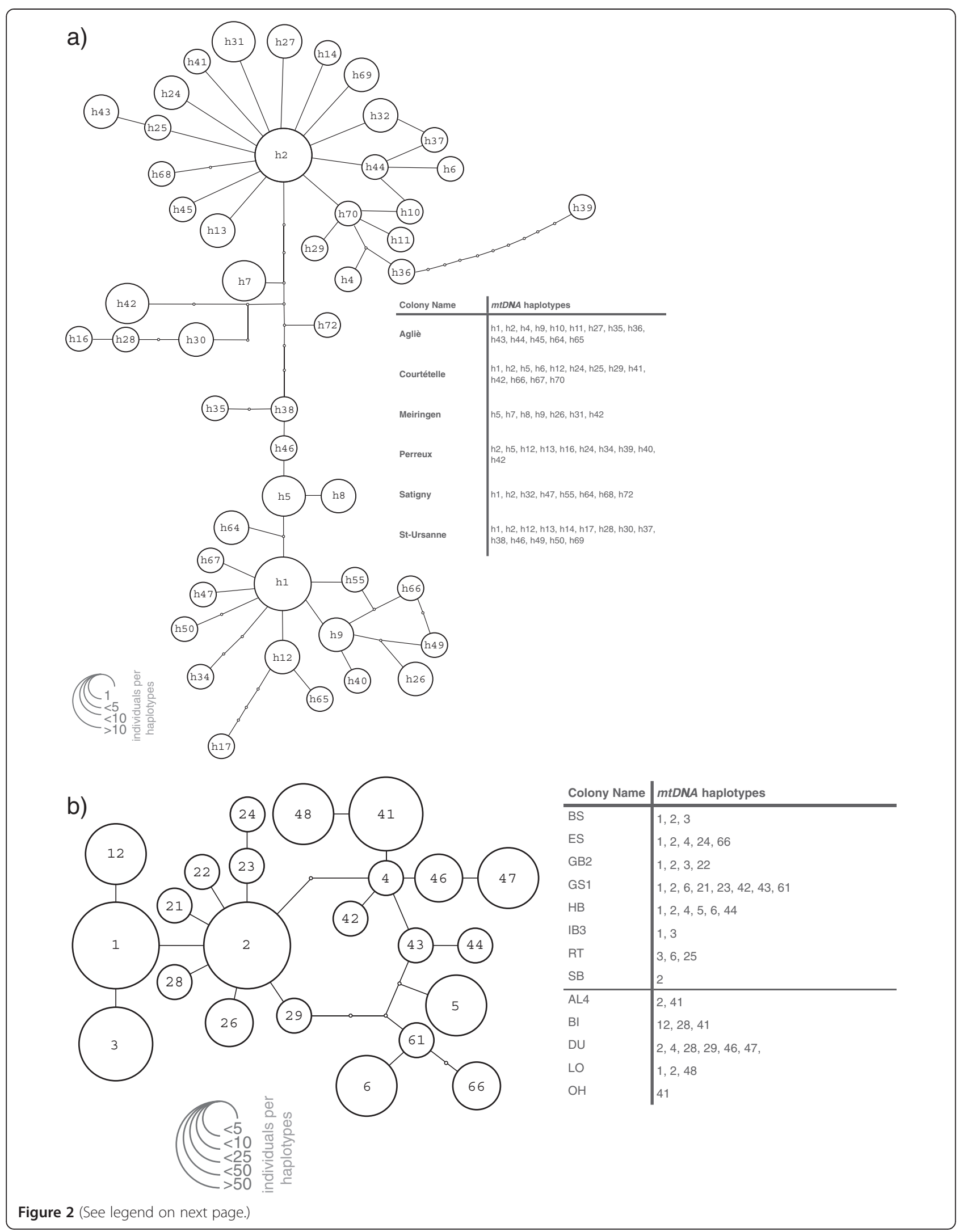


(See figure on previous page.)

Figure 2 Haplotype network for both parasite species. Haplotype network for (a) the 49 haplotypes determined by sequencing the cytochrome b (cytb) of 119 Spinturnix myoti, and (b) the 23 haplotypes for cytochrome b (cytb) for the 402 Spinturnix bechsteini included in this comparison, as previously analysed in Bruyndonkx et al. (2009b). The size of circles is proportional to the number of individuals sharing the same haplotype. For each species, the list of which haplotypes were found in each colony is given as an inset.

showed 93\% similarity between species. The overall structure of the haplotype networks does differ in that S. bechsteini has far fewer haplotypes (23 vs. 49$)$ despite a larger sample size, and does not exhibit two distinct haplotype clusters. This indicates that the pattern observed in $S$. myoti may be the result of admixture from the two glacial refugia of its host.

\section{Mite nucDNA}

No linkage disequilibrium was found between loci in either mite species. All six S. myoti populations showed highly significant deviations from Hardy-Weinberg equilibrium $(\mathrm{p}<0.0001)$, as a result of heterozygote deficiency $\left(\mathrm{F}_{\mathrm{IS}}\right.$ : 0.191-0.398). Similarly, S. bechsteini populations were not in Hardy-Weinberg equilibrium as a result of heterozygote deficiency $(\mathrm{p}<0.0001)$, with five exceptions (ES2007, GB2-2007, HB-2007, IB3-2002, OH). Microchecker indicated the possible presence of null alleles in all microsatellite loci for both species, but found no evidence for allelic dropout or stuttering. As discussed in the original marker description [36], we believe these heterozygote deficiencies are not the result of null alleles for several reasons. First, all markers show similarly heterozygote deviations indicating that null alleles would have to be present in all markers across both species. Second, mite populations may exhibit substantial inbreeding, as often observed in obligate parasite species eg. [50], as populations are often small and largely isolated. Therefore, although the possible presence of null alleles cannot be completely dismissed, we believe the markers to be biologically informative.

\section{S. myoti nucDNA}

Overall genetic variation in $S$. myoti was very high with total number of alleles per locus ranging from 13.13 to 18.13, and allelic richness ranging from 12.74 to 16.75 (Table 2a). A large proportion of these alleles were specific to one bat colony, with the number of private alleles ranging from 6 in Meiringen, to 22 in Aglié (mean = 13.17, Table 2a). Between bat colonies, S. myoti pairwise $\mathrm{F}_{\mathrm{ST}^{-}}$ values (Table 3a) showed very little differentiation $(0.002-0.026)$, and significant pairwise differentiation was only found between Aglié (separated from the other colonies by the alps) and all other colonies, and between Satigny and two other colonies (Meiringen and St. Ursanne). Pairwise $\mathrm{F}_{\mathrm{ST}^{-}}$and $\mathrm{G}_{\mathrm{ST}^{-}}{ }^{-v a l u e s}$ were slightly higher (-0.003-0.241 and 0.031-0.264 respectively) but did not differ strongly from the pairwise $\mathrm{F}_{\mathrm{ST}}$-values (data not shown). An AMOVA analysis found the vast majority of variation within mite populations (98.9\%; Table 4). Unlike in the mtDNA sequence, a significant, but very weak, correlation between genetic and geographic distances $\left(\beta=0.005, \mathrm{r}^{2}=0.362, \mathrm{p}=0.027\right.$; Additional file 1) was found, but $S$. myoti nuclear and mitochondrial genetic distance were nevertheless also significantly correlated $\left(\mathrm{r}^{2}=0.26, \mathrm{p}=0.049\right)$.

\section{S. bechsteini nucDNA}

Overall genetic variation in S. bechsteini was lower than that of $S$. myoti with 2.6 to 12.0 alleles per locus $($ mean $=6.83)$, and a mean allelic richness of 5.52 (Table 2c). The number of private alleles was also lower $(0-10$, mean $=1.79)$. However, it is important to note that the number of $S$. bechsteini populations was also much higher than in $S$. myoti thereby increasing the chance that we had sampled rare but widespread alleles at multiple locations.

Pairwise $\mathrm{F}_{\mathrm{ST}}$-values among populations were much higher in S. bechsteini than in S. myoti (0.052-0.475, mean = 0.228 ; Table 3c) as well as those of its host (Table 3d), and all $S$. bechsteini populations were significantly differentiated from one another. Pairwise $\mathrm{F}_{\mathrm{ST}^{-}}$and $\mathrm{G}^{\prime \prime} \mathrm{ST}^{-v a l u e s}$ showed even more exacerbated differentiation between mite populations (0.333-0.929 and 0.334-0.93 respectively), but again closely followed the pattern seen in the pairwise

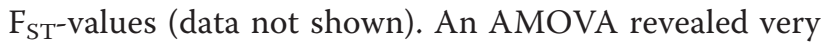
similar patterns as in $S$. myoti, with the majority of the sampled variation found within $S$. bechsteini populations (73.3\%; Table 4). Nevertheless, there was also significant differentiation among mite populations $(\mathrm{p}<0.001)$.

Between the spatially distant regions of Lower Franconia (LF) and Rhineland-Palatine (RP), $45 \%$ of the alleles were shared. Pairwise $\mathrm{F}_{\mathrm{ST}}$-values of $S$. bechsteini between bat colonies from differing regions were very similar to those between bat colonies from the same region (within $\mathrm{LF}=0.215$, within $\mathrm{RP}=0.235$, between regions $=0.236$ ) Indeed, a hierarchical AMOVA including regions found only $2.4 \%$ of the variation between regions, with the vast majority of variation found within $S$. bechsteini populations $(72.9 \%)$ and among bat colonies within regions (22.5\%; Table 4). No correlation was found between geographic and genetic distance $\left(r^{2}=0.027\right.$, $\mathrm{p}=0.39$; Additional file 1).

A clear temporal genetic differentiation $\left(\mathrm{F}_{\mathrm{ST}}=0.085\right.$ 0.254 , mean $=0.147$ ) in $S$. bechsteini was evident in all five bat colonies sampled for mites in 2002 and 2007. 
Table 3 Pariwise $\Phi_{\mathrm{ST}}$ and $\mathrm{F}_{\mathrm{ST}}$-values for all species

\begin{tabular}{|c|c|c|c|c|c|c|}
\hline \multicolumn{7}{|l|}{ a) S. myoti } \\
\hline Mite $\Phi_{S T} \backslash F_{s t}$ & Agliè & Courtételle & Meiringen & Perreux & Satigny & St-Ursanne \\
\hline Agliè & - & $0.014^{*}$ & $0.018^{*}$ & $0.014^{*}$ & $0.026^{*}$ & $0.016^{*}$ \\
\hline Courtételle & -0.02 & - & 0.004 & 0.013 & 0.004 & 0.002 \\
\hline Meiringen & 0.05 & 0.02 & - & 0.01 & $0.015^{*}$ & 0.004 \\
\hline Perreux & -0.01 & -0.04 & 0.01 & - & 0.015 & 0.009 \\
\hline Satigny & $0.11^{*}$ & 0.04 & $0.08^{*}$ & 0.05 & - & $0.012^{*}$ \\
\hline St-Ursanne & 0.03 & -0.01 & 0.03 & -0.01 & 0.02 & 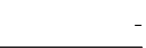 \\
\hline \multicolumn{7}{|l|}{ b) M. myotis } \\
\hline Host $\Phi_{S T} \backslash F_{S T}$ & Agliè & Courtételle & Meiringen & Perreux & Satigny & St-Ursanne \\
\hline Agliè & - & $0.043^{*}$ & $0.057^{*}$ & $0.034^{*}$ & $0.035^{*}$ & $0.036^{*}$ \\
\hline Courtételle & $0.72^{*}$ & - & 0.016 & -0.001 & 0.009 & -0.003 \\
\hline Meiringen & $0.71^{*}$ & 0.04 & - & 0.0004 & 0.007 & 0.014 \\
\hline Perreux & $0.70^{*}$ & $0.15^{*}$ & $0.12^{*}$ & - & 0.006 & 0.003 \\
\hline Satigny & $0.37^{*}$ & $0.21^{*}$ & $0.20^{*}$ & $0.18^{*}$ & - & 0.002 \\
\hline St-Ursanne & $0.73^{*}$ & 0 & 0.05 & $0.18^{*}$ & $0.22^{*}$ & \\
\hline
\end{tabular}

\section{c) S. bechsteini}

LF

\begin{tabular}{|c|c|c|c|c|c|c|c|c|c|c|c|c|c|c|}
\hline \multirow{2}{*}{\multicolumn{2}{|c|}{ Mite $\Phi_{\mathrm{ST}} \mathrm{I} \mathrm{F}_{\mathrm{st}}$}} & & & & & & & & & & & & & \\
\hline & & BS & ES & GB2 & GS1 & $\mathrm{HB}$ & IB3 & RT & SB & AL4 & $\mathrm{BI}$ & DU & LO & $\mathrm{OH}$ \\
\hline \multirow[t]{8}{*}{$1 \mathrm{~F}$} & Blutsee & - & $0.217^{*}$ & $0.255^{*}$ & $0.202^{*}$ & $0.316^{*}$ & $0.126^{*}$ & $0.153^{*}$ & $0.351^{*}$ & $0.260^{*}$ & $0.243^{*}$ & $0.185^{*}$ & $0.275^{*}$ & $0.406^{*}$ \\
\hline & Einsiedeln & $0.54^{*}$ & - & $0.174^{*}$ & $0.084^{*}$ & $0.184^{*}$ & $0.275^{*}$ & $0.068^{*}$ & $0.221^{*}$ & $0.130^{*}$ & $0.123^{*}$ & $0.145^{*}$ & $0.177^{*}$ & $0.365^{*}$ \\
\hline & Guttenberg 2 & $0.73^{*}$ & $0.51^{*}$ & - & $0.131^{*}$ & $0.283^{*}$ & $0.307^{*}$ & $0.116^{*}$ & $0.315^{*}$ & $0.180^{*}$ & $0.186^{*}$ & $0.186^{*}$ & $0.215^{*}$ & $0.421^{*}$ \\
\hline & Gramschatz 1 & $0.22^{*}$ & $0.16^{*}$ & $0.36^{*}$ & - & $0.159^{*}$ & $0.226^{*}$ & $0.052^{*}$ & $0.213^{*}$ & $0.133^{*}$ & $0.130^{*}$ & $0.079^{*}$ & $0.098^{*}$ & $0.312^{*}$ \\
\hline & Höchberg & $0.88^{*}$ & $0.75^{*}$ & $0.87^{*}$ & $0.60^{*}$ & - & $0.348^{*}$ & $0.171^{*}$ & $0.299^{*}$ & $0.228^{*}$ & $0.210^{*}$ & $0.204^{*}$ & $0.248^{*}$ & $0.422^{*}$ \\
\hline & Irtenberg 3 & $0.90^{*}$ & $0.83^{*}$ & $0.91^{*}$ & $0.69^{*}$ & $1.00^{*}$ & - & $0.158^{*}$ & $0.372^{*}$ & $0.322^{*}$ & $0.284^{*}$ & $0.213^{*}$ & $0.301^{*}$ & $0.458^{*}$ \\
\hline & Reutholz & $0.62^{*}$ & $0.33^{*}$ & $0.53^{*}$ & $0.27^{*}$ & $0.66^{*}$ & $0.53^{*}$ & - & $0.233^{*}$ & $0.121^{*}$ & $0.149^{*}$ & $0.113^{*}$ & $0.135^{*}$ & $0.309^{*}$ \\
\hline & Steinbach & $0.87^{*}$ & $0.72^{*}$ & 0.110 & $0.55^{*}$ & $1.00^{*}$ & $1.00^{*}$ & $0.66^{*}$ & - & $0.250^{*}$ & $0.244^{*}$ & $0.267^{*}$ & $0.239^{*}$ & $0.475^{*}$ \\
\hline \multirow[t]{5}{*}{ RP } & Altrich 4 & $0.83^{*}$ & $0.61^{*}$ & $0.77^{*}$ & $0.50^{*}$ & $0.94^{*}$ & $0.96^{*}$ & $0.56^{*}$ & $0.94^{*}$ & - & $0.214^{*}$ & $0.173^{*}$ & $0.163^{*}$ & $0.314^{*}$ \\
\hline & Bitburg & $0.72^{*}$ & $0.47^{*}$ & $0.64^{*}$ & $0.40^{*}$ & $0.77^{*}$ & $0.83^{*}$ & $0.45^{*}$ & $0.78^{*}$ & $0.60^{*}$ & - & $0.138^{*}$ & $0.181^{*}$ & $0.379^{*}$ \\
\hline & Duppach & $0.59^{*}$ & $0.29^{*}$ & $0.47^{*}$ & $0.25^{*}$ & $0.62^{*}$ & $0.70^{*}$ & $0.31^{*}$ & $0.61^{*}$ & $0.52^{*}$ & $0.41^{*}$ & - & $0.158^{*}$ & $0.382^{*}$ \\
\hline & Longuich & $0.50^{*}$ & $0.26^{*}$ & $0.25^{*}$ & $0.16^{*}$ & $0.64^{*}$ & $0.72^{*}$ & $0.34^{*}$ & $0.42^{*}$ & $0.54^{*}$ & $0.44^{*}$ & $0.29^{*}$ & - & $0.243^{*}$ \\
\hline & Orenhofen & $0.88^{*}$ & $0.76^{*}$ & $0.87^{*}$ & $0.62^{*}$ & $1.00^{*}$ & $1.00^{*}$ & $0.67^{*}$ & $1.00^{*}$ & 0.030 & $0.72^{*}$ & $0.63^{*}$ & $0.65^{*}$ & \\
\hline
\end{tabular}

d) M. bechsteinii

\begin{tabular}{|c|c|c|c|c|c|c|c|c|c|c|}
\hline & \multirow[b]{2}{*}{ Host $m t F_{S T} \backslash F_{S T}$} & \multicolumn{7}{|c|}{ LF } & \multicolumn{2}{|c|}{$\mathrm{RP}$} \\
\hline & & ES & GB2 & GS1 & $\mathrm{HB}$ & IB3 & RT & SB & $\mathrm{BI}$ & DU \\
\hline \multirow[t]{8}{*}{ LF } & Blutsee & 0.023 & 0.004 & 0.005 & 0.008 & 0.008 & 0.011 & 0.006 & 0.072 & 0.016 \\
\hline & Einsiedeln & - & $0.036^{*}$ & $0.032^{*}$ & 0.044 & 0.032 & 0.03 & $0.036^{*}$ & 0.5 & $0.356^{*}$ \\
\hline & Guttenberg 2 & $0.245^{*}$ & - & 0.007 & $0.010^{*}$ & 0.002 & $0.010^{*}$ & 0.006 & 0.448 & $0.445^{*}$ \\
\hline & Gramschatz 1 & -0.001 & $0.252^{*}$ & - & $0.018^{*}$ & 0.005 & 0.004 & 0.004 & 0.488 & 0.351 \\
\hline & Höchberg & 0.075 & $0.142^{*}$ & $0.087^{*}$ & - & 0.009 & $0.028^{*}$ & 0.01 & 0.375 & $0.341^{*}$ \\
\hline & Irtenberg 3 & $0.260^{*}$ & $0.239^{*}$ & $0.259^{*}$ & $0.148^{*}$ & - & 0.014 & 0.005 & 0.318 & 0.28 \\
\hline & Reutholz & $0.388^{*}$ & $0.373^{*}$ & $0.412^{*}$ & $0.304^{*}$ & $0.201^{*}$ & - & 0.014 & 0.072 & 0.211 \\
\hline & Steinbach & $0.333^{*}$ & $0.274^{*}$ & $0.320^{*}$ & $0.195^{*}$ & 0.004 & $0.205^{*}$ & - & 0.333 & 0.312 \\
\hline
\end{tabular}


Table 3 Pariwise $\Phi_{\mathrm{ST}}$ and $\mathbf{F}_{\mathrm{ST}}$-values for all species (Continued)

\begin{tabular}{llllllllll}
\hline RP $\quad$ Bitburg & 0.028 & $0.004^{*}$ & $0.009^{*}$ & $0.017^{*}$ & $0.009^{*}$ & 0.015 & $0.012^{*}$ & - & 0.013 \\
& Duppach & $0.042^{*}$ & $0.015^{*}$ & $0.013^{*}$ & $0.030^{*}$ & $0.022^{*}$ & $0.010^{*}$ & $0.019^{*}$ & $0.311^{*}$ \\
\hline
\end{tabular}

Pairwise $\Phi_{\mathrm{ST}}$ (below the diagonal) and $\mathrm{F}_{\mathrm{ST}}$-values (above the diagonal) for a) Spinturnix myoti, b) Myotis myotis c) Spinturnix bechsteini d) Myotis bechsteinii. For M. bechsteinii values below the diagonal are pairwise $\mathrm{F}_{\mathrm{ST}}$-values of mitochondrial microsatellites. Asterisks indicate significant differentiation $(p<0.05$ ).

This level of differentiation is comparable to the average differentiation seen between all sampling events between different bat colonies within one year $(0.146$ and 0.238 for 2002 and 2007 respectively). Pairwise differentiation between the five colonies was not correlated between 2002 and 2007 (Spearman's rank correlation: $r=-0.360$, $\mathrm{p}=0.238$ ), indicating no stable sub-structuring within the region. Within individual bat colonies, only $26.0-41.2 \%$ of alleles were conserved across sampling events, also indicating strong temporal turnover of the S. bechsteini populations.

In all, our results for nucDNA closely mirror those of the previously analysed mtDNA [23]. It is therefore unsurprising that a significant correlation between nuclear and mitochondrial $\mathrm{F}_{\mathrm{ST}}$-values can be seen $\left(\mathrm{r}^{2}=0.34, \mathrm{p}=0.001\right)$.

\section{Comparison with host}

We applied mantel test analysis to examine the correlation between the genetic distances of hosts and parasites (Table 5). In neither of the host-parasite pairs were any of the pairwise $\Phi_{\mathrm{ST}}$ or $\mathrm{F}_{\mathrm{ST}}$-values significantly correlated between species after correcting for geographic distance. A plot of the pairwise genetic distance $\left(\mathrm{F}_{\mathrm{ST}} / 1-\mathrm{F}_{\mathrm{ST}}\right)$ between populations of hosts and parasites reveals that this lack of correlation is due to large variation in parasite pairwise differentiation at low levels of host genetic differentiation in both species pairs (Figure 3a,b). Additionally, in M. bechsteinii and S. bechsteini, no effect of geographic distance on host and parasite pairwise genetic differentiation can be observed (Figure 3b).

A STRUCTURE analysis revealed several interesting differences in both pairs of host and parasite (Figure 4). In $S$. myoti no clear sub-structuring was observed
(Figure 4a), whereas in its host, M. myotis, the southernmost colony (Aglié) appears to cluster separately (Figure $4 \mathrm{~b}$ ). This is concordant with phylogeographic analyses, which have indicated that populations of $M$. myotis south of the Alps originate from a different glacial refugium [19], although this barrier is evidently not present for its mites. In $M$. bechsteinii and S. bechsteini clear substructuring according to host colony can be observed in the parasite (Figure 4c), while host colonies show no evidence for population sub-structuring (Figure 4d) as is expected with an outbreeding mating system such as swarming [16].

Finally, since host colony size between species appears to have a large effect on the population genetic structure of its parasites, we used Spearman's rank correlation tests to investigate whether variation in host colony size within each host was correlated with parasite diversity indices (Table 6). Host colony size was not significant correlated with any of the parasite genetic indices after Bonferroni correction, although there was a positive trend between parasite allelic richness and host colony size in both species pairs.

\section{Discussion}

The population genetic structure of parasite populations is strongly influenced by both its own life history as well as the life history and social system of its host. Here, we compared the population genetic structure of both host and parasite in two closely related systems where parasite life histories are nearly identical, but hosts differ substantially in social system. We find that the population genetic structure of the two mite species differs strongly as a result of the social system of their hosts, which is in

Table 4 Analysis of Molecular variance (AMOVA) for both parasite species

\begin{tabular}{|c|c|c|c|c|}
\hline Source of variation & d.f. & Sum of squares & Variance components & Percentage of variation \\
\hline \multicolumn{5}{|l|}{ Spinturnix myoti } \\
\hline Among colonies & 5 & 30.96 & 0.04 & $1.1^{*}$ \\
\hline Among individuals, within colonies & 111 & 512.39 & 0.96 & $26.0^{*}$ \\
\hline Within individuals & 117 & 315.5 & 2.69 & 72.9 \\
\hline \multicolumn{5}{|l|}{ Spinturnix bechsteini } \\
\hline Among regions & 1 & 40.39 & 0.05 & $2.4^{*}$ \\
\hline Among colonies, within regions & $11(12)$ & $269.92(309.64)$ & $0.5(0.52)$ & $22.5^{*}\left(23.3^{*}\right)$ \\
\hline Among individuals, within colonies & 289 & $494.33(518.55)$ & $0.05(0.08)$ & $2.2^{*}\left(3.4^{*}\right)$ \\
\hline Within individuals & 302 & $487(496)$ & $1.61(1.64)$ & $72.9(73.3)$ \\
\hline
\end{tabular}

Analysis of molecular variance for a) Spinturnix myoti and b) Spinturnix bechsteini. For S. bechsteini a hierarchical AMOVA including region as an additional factor is shown, with the values of a non-hierarchical AMOVA given in parentheses. Asterisks indicate significant contributions. 
Table 5 Correlation between host and parasite genetic distance

\begin{tabular}{|c|c|c|c|c|}
\hline & \multicolumn{2}{|c|}{$\begin{array}{l}\text { S. myoti/ } \\
\text { M. myotis }\end{array}$} & \multicolumn{2}{|c|}{$\begin{array}{l}\text { S. bechsteini/ } \\
\text { M. bechsteinii }\end{array}$} \\
\hline & $\beta$ & $R^{2}$ & $\beta$ & $\mathrm{R}^{2}$ \\
\hline Mite mtDNA - Host mtDNA & -2.59 & 0.139 & -0.329 & 0.115 \\
\hline Mite mtDNA - Host nDNA & -0.17 & 0.125 & -3.33 & 0.025 \\
\hline Mite nDNA - Host mtDNA & 0.003 & 0.022 & -0.101 & 0.097 \\
\hline Mite nDNA - Host nDNA & 0.343 & 0.013 & -0.04 & 0.08 \\
\hline
\end{tabular}

Correlations (partial mantel) between host and parasite genetic differentiation corrected for geographic distance. For each pair the slope $(\beta)$ and the variance explained by the model $\left(\mathrm{R}^{2}\right)$ are given. No correlations were significant after correcting for distance.

agreement with our predictions based on the differences in social system of their hosts.

\section{Parasite population genetic structure}

In $S$. myoti, overall mtDNA haplotype diversity (49 haplotypes in 120 individuals) and nuclear genetic diversity were high (mean 16.69 alleles per locus in only 20 individuals per colony). This diversity is higher than that seen in its host, M. myotis, and may be the result of admixture between parasites originating from several glacial refugia or species, coupled with sufficiently large host maternity colony size to prevent strong bottlenecks in the mites. Between M. myotis colonies, we found very low genetic differentiation and no evidence for population substructuring in the mites. Indeed the vast majority of genetic diversity of $S$. myoti occurred within bat maternity colonies suggesting a large amount of parasite exchange between hosts originating from different maternity colonies outside of the maternity period, resulting in a highly diverse and panmictic population. These results are concordant with the observation of other empirical studies on host-parasite co-variation eg. [9], that have found levels of parasite gene flow much higher than originally predicted [51]. Notably, the extensive mixing of parasites outside of the breeding period has also been found in ectoparasitic lice of birds, where the genetic structure of parasites was largely shaped by the dispersal of lice at communal wintering sites [10].

The population genetic structure of S. bechsteini contrasted sharply with that of S. myoti. Overall nuclear genetic diversity was lower, but still higher than that of its host, M. bechsteinii. All S. bechsteini populations were significantly differentiated from one another, and it was possible to assign mites to subpopulations according to their host colony of origin (Figure 4). This is likely to be due to strong genetic drift within host colonies as a result of their small maternity colony size as well as their tendency to hibernate without body contact with conspecifics. Both factors combine to drastically limit the number mites present within a host colony when the colonies reform in spring. Nevertheless, S. bechsteini populations within colonies were temporally unstable (between sampling years mean $\mathrm{F}_{\mathrm{ST}}=0.147$ for nucDNA) suggesting that gene flow between colonies is still substantial. In agreement with this finding, Bruyndonckx et al. [23] observed a large turnover in haplotypes between sampling years. Despite this strong differentiation among colonies and years at a local scale, differentiation of $S$. bechsteini between colonies from spatially distinct regions was not higher than within regions, suggesting that overall genetic diversity of the $S$. bechsteini population at a regional level is Stable. A comparable pattern of strong population genetic substructure and high levels of genetic drift is also seen in the parasites of other host taxa with similarly closed societies as in Bechstein's bats, e.g. in the ectoparasitic chewing lice of pocket gophers rev. in [11].

Relationship between parasite and host population structure No correlation was found between host and parasite genetic differentiation in either of the species. Additionally, within each of the two host species, colony size did not significantly correlate with any of the parasite genetic indices, although a trend of increasing allelic richness with increased colony size was present in both species pairs.

\section{Influence of host social system}

Our results indicate that differences between hosts in colony size, mating system, and in particular the degree of social interaction outside of the summer maternity roosts have a large effect on parasite genetic structure. $M$. bechsteinii has a remarkably closed social system, with very strong natal philopatry and vastly limited social interaction outside of the summer maternity season [52,53]. Previously, it has also been shown that $M$. bechsteinii actively reduces the intensity of another ectoparasite species that deposits its larval stages in the roosts via roost-switching behaviour (bat flies; [54]). It thus seems possible that the much more closed social system of $M$. bechsteinii, as compared to M. myotis, has also evolved to restrict the infestation of other parasites, such as wing mites, that depend on body contact between hosts.

In M. myotis, our data provide no evidence for such anti-parasite behaviour. While this may be because there is an insufficient number of alternative roosts to increase population subdivision into smaller colonies, social interaction during other periods such as mating and hibernation is also extensive, thereby further permitting parasite exchange.

Several other factors probably have also influenced the genetic structure of both mite species, but these factors do not detract from the influence of host social structure. For example, the phylogeographic history of both mite species is quite different, and may explain the differences in the number of haplotypes and nucleotide diversity 

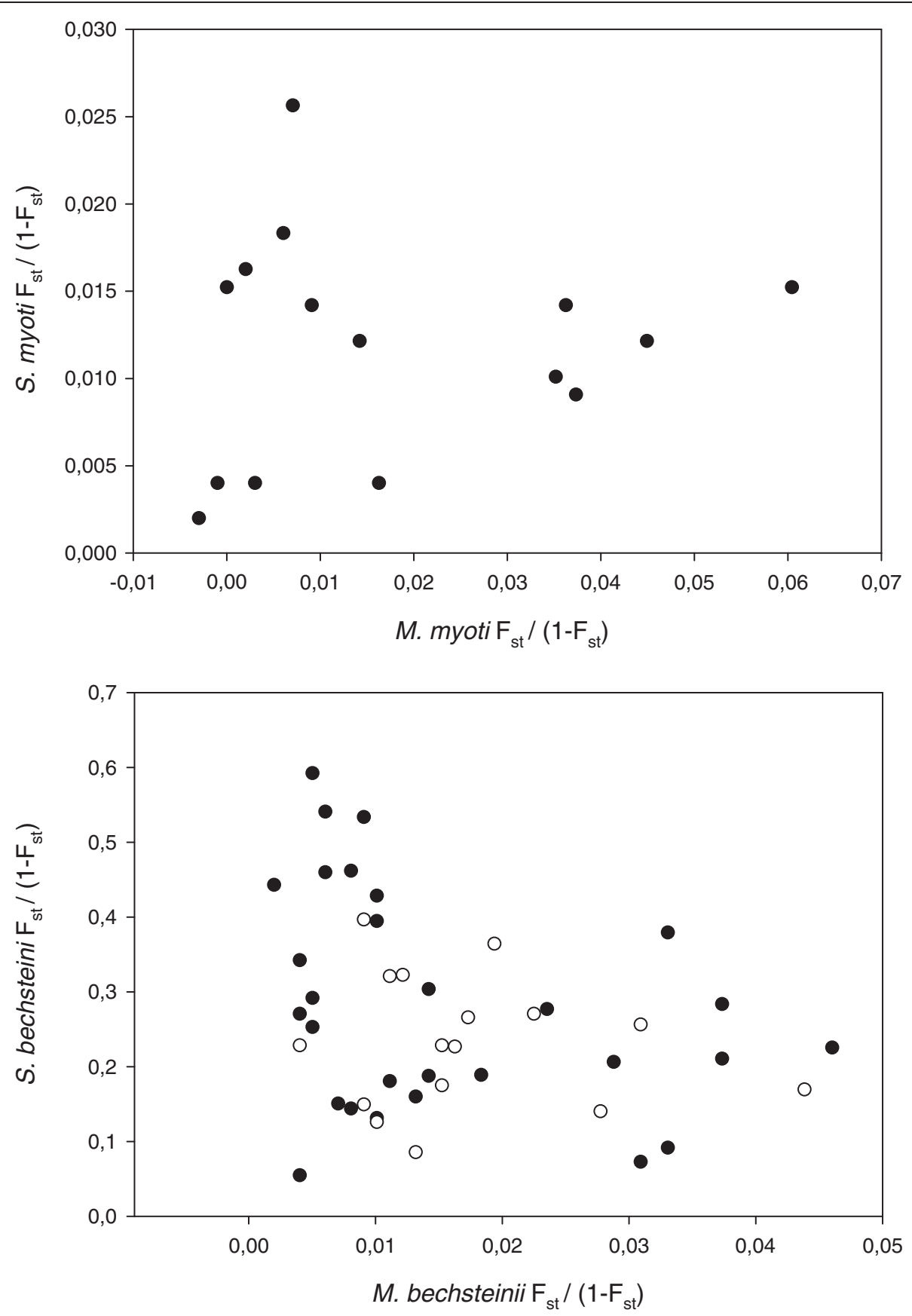

Figure 3 Comparison of host and parasite genetic difference. Pairwise genetic distance $\left(F_{S T} / 1-F_{S T}\right)$ estimates between populations of hosts and parasites for a) Myotis myotis and Spinturnix myoti, and $\mathbf{b})$ Myotis bechsteinii and Spinturnix bechsteini. For the latter pair, the symbols indicate whether colonies were within the same region (closed circles) or from different regions (open circles).

found in the mtDNA sequences (compare Figure $2 \mathrm{a}$ and Figure 2b), and likely also the diversity found in the nucDNA microsatellites. Nevertheless, these macrogeographic differences between the two mite species cannot explain the differences seen in population genetic structure on a microgeographic scale. For example, almost all $M$. bechsteinii colonies harboured S. bechsteini populations that were monotypic or had only two haplotypes as a result of the strong winter bottleneck. This contrasts sharply with the sampled populations of $S$. myoti, in which we found between seven and fourteen haplotypes in only twenty samples per populations. Thus, although the history of both species has certainly influenced the overall nucleotide and genetic diversity observed, the differences in genetic structure observed on a population level are still primarily the result of differences in host 
a) S. myoti $(\mathrm{K}=2)$

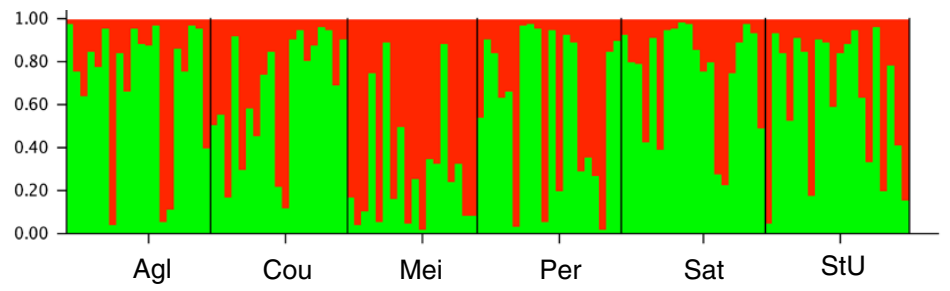

b) M. myotis $(\mathrm{K}=3)$

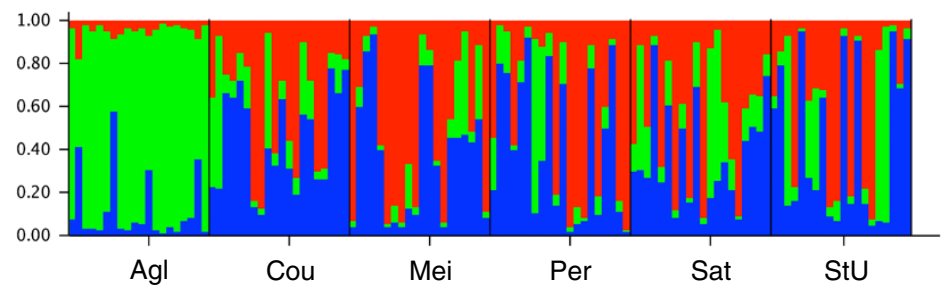

C) S. bechsteini $(\mathrm{K}=7)$

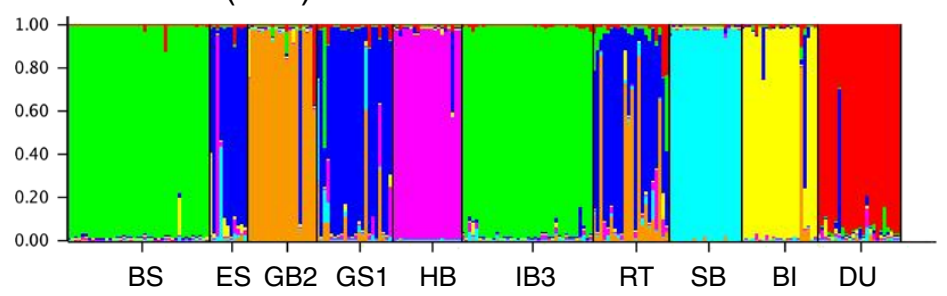

d) M. bechsteinii $(\mathrm{K}=2)$

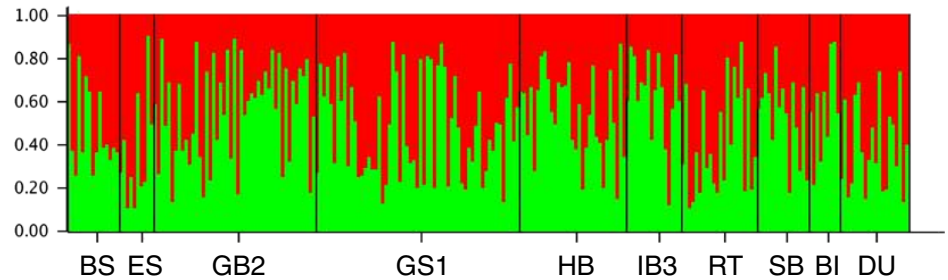

Figure 4 STRUCTURE analysis for all species. STRUCTURE results for a) Spinturnix myoti, b) Myotis myotis c) Spinturnix bechsteini d) Myotis bechsteinii. Colony names correspond to the abbreviations given in Tab. 2. Results are shown for the number of subpopulations with the best $\Delta \mathrm{K}$ and highest log likelihood ( $\mathrm{S}$. bechsteini $\mathrm{K}=7, \mathrm{M}$. myotis $\mathrm{K}=3$ ). In S. myoti and $\mathrm{M}$. bechsteinii no discernable population sub-structuring was found, with strongest support being found for $\mathrm{K}=1$. For these species $\mathrm{K}=2$ is shown to illustrate the lack of structuring when multiple subpopulations are assumed.

Table 6 Correlation between host colony size and parasite genetic parameters

\begin{tabular}{lccccc}
\hline & \multicolumn{2}{c}{ M. myotis } & & \multicolumn{2}{c}{ M. bechsteini } \\
\cline { 2 - 3 } \cline { 6 - 6 } Parasite trait & $\boldsymbol{\rho}$ & $\boldsymbol{p}$ & & $\boldsymbol{\rho}$ & $\boldsymbol{p}$ \\
\hline Number of haplotypes & 0.75 & 0.09 & & 0.28 & 0.26 \\
Nucleotide diversity & -0.26 & 0.61 & & 0.29 & 0.24 \\
Expected heterozygosity & 0.64 & 0.17 & & 0.49 & 0.12 \\
Observed heterozygosity & 0.41 & 0.43 & & 0.16 & 0.64 \\
Allelic richness & 0.9 & 0.015 & & 0.45 & 0.06 \\
\hline
\end{tabular}

Spearman rank correlations between host colony size and parasite genetic parameters. For each pair the correlation coefficient $(\rho)$ and the P-value are given. No correlations were significant after Bonferroni correction $(p<0.01)$. social system. Another major difference between the two mite species is the potential use of secondary host, with identical social system, in S. myoti. Here too, the social systems of the hosts play a role, as the closed social system of $M$. bechsteinii minimizes contact between conspecifics and virtually eliminates contact with other species. Therefore, while the possible use of additional hosts in S. myoti may increase its effective population size and potentially also increase its dispersal opportunities, these factors can also be (indirectly) attributed to the differing social systems of the hosts. 


\section{Consequences for parasite evolutionary potential}

The observed differences in population genetic structure of the two mite species should strongly influence their evolutionary potential. In S. bechsteini, the influence of genetic drift strongly limits the likelihood that any local adaptation to its host maternity colony is able to persist and spread. S. myoti, in contrast, has a much more stable population genetic structure as well as a higher rate of gene flow relative to its host, and may therefore be able to locally adapt to its major host, M. myotis.

The observed difference in population genetic structure between the mites analysed here also have broader consequences for general investigations of parasites in relation to host social system. For example, they suggest that parasite species with very similar life histories may have vastly different evolutionary potentials depending on not only the life history but also the social system of their hosts. As a result, we conclude that host social system can be effective beyond reducing the overall chance of parasite infection, by potentially also playing a role in limiting the evolutionary potential of, often unavoidable, parasites. Therefore, comparative and theoretical studies of host-parasite interactions that investigate the role of host population size and community modularity eg [55] will be critical not only in understanding parasite transmission, but also in investigating the evolutionary potential of established parasite species.

\section{Conclusions}

In conclusion, our results suggest that host social system can strongly influence parasite population genetic structure. Most notably, host maternity colony size appears to strongly affect the genetic drift experienced by the different parasite species and the social organization of the host outside of the maternity period affects the opportunities for parasite exchange between individuals from remote maternity colonies. We conclude that such differences in host social system have consequences for both the direct costs of parasites as well as the general threat of disease transmission. Therefore, the concurrent genetic analysis of host and parasite allows for inferences about the movements and social contacts of host species, as well as broader conclusions regarding host-parasite dynamics.

\section{Availability of supporting data}

The datasets for S. myoti and S. bechsteini supporting the results of this article may be requested from the corresponding author. The haplotype sequences for $S$. myoti have been deposited in GenBank under ascension numbers [KJ174107-KJ174155].

\section{Additional file}

Additional file 1: Supplementary analyses to: The effect of host social system on parasite population genetic structure: comparative population genetics of two ectoparasitic mites and their bat hosts.

\section{Competing interests}

The authors declare that they have no competing interests.

\section{Authors' contributions}

All authors designed the research and participated in sample collection; JvS and NB performed the molecular genetic studies and data analysis; and JVS supported by all authors wrote the paper. All authors read and approved the final manuscript.

\section{Acknowledgements}

We would like to thank Michel Blanc, Pascal Roduit, Julien Oppliger, Peter Zingg, Elena Patriarca, Paolo Debernardi, Karsten Reckardt, Isabelle Henry, Markus Melber, Daniela Fleischmann, Manfred Weishaar, and many others for their help during collection of mites. We are grateful to Thomas Broquet, who provided useful comments on the analyses and interpretations, and to Nathalie Tzaud, Sébastien Nusslé, Nelly DiMarco, Philippe Busso and Jari Garbely for laboratory facilities. Funding was provided by grant

31003A_138187 from the Swiss National Science Foundation and by la Fondation Herbette to PC, as well as the Julius Klaus Foundation and the German Science Foundation (DFG KE 746/3-1 and KE 746/4-1) to GK. JvS is funded by the Volkswagen Foundation, and the International Max Planck Research School for Organismal Biology.

\section{Author details}

${ }^{1}$ Department of Behavioural Ecology and Evolutionary Genetics, Max Planck Institute for Ornithology, Eberhard-Gwinner-Strasse, 82319 Seewiesen, Germany. ${ }^{2}$ Zoological Institute \& Museum, Greifswald University, J.-S.-Bach-Str. 11 / 12 , D-17489 Greifswald, Germany. ${ }^{3}$ Department of Ecology and Evolution, University of Lausanne, Biophore, CH-1015 Lausanne, Switzerland.

Received: 17 September 2013 Accepted: 17 January 2014 Published: 30 January 2014

\section{References}

1. Loehle C: Social barriers to pathogen transmission in wild animal populations. Ecology 1995, 76:326-335.

2. Ezenwa VO: Host social behavior and parasitic infection: a multifactorial approach. Behav Ecol 2004, 15(3):446-454.

3. Hart BL: Behavioral adaptations to pathogens and parasites: five strategies. Neurosci Biobehav Rev 1990, 14(3):273-294.

4. Gandon S, Michalakis Y: Local adaptation, evolutionary potential and host-parasite coevolution: interactions between migration, mutation, population size and generation time. J Evol Biol 2002, 15:451-462.

5. Nadler SA: Microevoltion and the genetic structure of parasite populations. J Parasitol 1995, 81:395-403.

6. Altizer $\mathrm{S}$, Nunn $\mathrm{CL}$, Thrall PH: Social organization and parasite risk in mammals: Integrating theory and empirical studies. Annu Rev Ecol Evol Syst 2003, 34:517-547.

7. Gandon S, Nuismer SL: Interactions between genetic drift, gene flow, and selection mosaics drive parasite local adaptation. Am Nat 2009, 173:212-224.

8. Nuismer SL, Gomulkiewicz R, Ridenhour BJ: When is correlation coevolution? Am Nat 2010, 175(5):525-537.

9. McCoy KD, Boulinier T, Tirard C: Comparative host-parasite population structures: disentangling prospecting and dispersal in the Black-Legged Kittiwake Rissa tridactyla. Mol Ecol 2005, 14:2825-2838.

10. Gómez-Díaz E, González-Solís J, Peinado MA, Page RDM: Lack of hostdependent genetic structure in ectoparasites of Calonectris shearwaters. Mol Ecol 2007, 16(24):5204-5215.

11. Hafner MS, Demastes JW, Spradling TA, Reed DL: Cophylogeny between pocket gophers and chewing lice. University of Chicago Press; 2003.

12. Rudnick A: A revision of the mites of the family Spinturnicidae (Acarina) Univ Calif Publ Entomol 1960, 17:157-284.

13. Deunff J, Walter G, Bellido A, Volleth M: Description of a cryptic species, Spinturnix bechsteini n. sp. (Acari: Mesostigmata, Spinturnicidae), parasite 
of Myotis bechsteinii (Kuhl, 1817) (Chiroptera: Vespertilionidae) by using ecoethology of host bats and statistical methods. J Med Entomol 2004, 41:826-832.

14. Zahn A, Dippel B: Male roosting habits and mating behaviour of Myotis myotis. J Zool 1997, 243:659-674.

15. Kerth G, Morf L: Behavioral and genetic data suggest that Bechstein's bat predominately mate outside the breeding habitat. Ethology 2004, 110:987-999.

16. Kerth G, Kiefer A, Trappmann C, Weishaar M: High gene diversity at swarming sites suggest hot spots for gene flow in the endangered Bechstein's bat. Conserv Genet 2003, 4(4):491-499.

17. Krapp F: Handbuch der Säugetiere Europas. Bd. 4/I: Fledertiere (Chiroptera) II, Vespertilionidae 2, Mollosidae, Nycteridae. Wiebelsheim: Aula Verlag; 2004.

18. Hutterer R: Bat migrations in Europe: a review of banding data and literature, vol. 28. Bonn: Federal Agency for Nature Conservation; 2005.

19. Ruedi M, Walter S, Fischer MC, Scaravelli D, Excoffier L, Heckel G: Italy as a major ice age refuge area for the bat Myotis myotis (Chiroptera : Vespertilionidae) in Europe. Mol Ecol 2008, 17(7):1801-1814.

20. Kerth G, Petrov B, Conti A, Anastasov D, Weishaar M, Gazaryan S, Jaquiery J, Konig B, Perrin N, Bruyndonckx N: Communally breeding Bechstein's bat have a stable social system that is independent from the postglacial history and location of the populations. Mol Ecol 2008, 17:2368-2381.

21. Bruyndonckx N, Dubey S, Ruedi M, Christe P: Molecular cophylogenetic relationships between European bats and their ectoparasitic mites (Acari, Spinturnicidae). Mol Phylogenet Evol 2009, 51(2):227-237.

22. Giorgi MS, Arlettaz R, Guillaume F, Nussle S, Ossola C, Vogel P, Christe P: Causal mechanisms underlying host specificity in bat ectoparasites. Oecologia 2004, 138(4):648-654

23. Bruyndonckx N, Henry I, Christe P, Kerth G: Spatio-temporal population genetic structure of the parasitic mite Spinturnix bechsteini is shaped by its own demography and the social system of its bat host. Mol Ecol 2009, 18(17):3581-3592.

24. Christe P, Glaziot O, Evanno G, Bruyndonckx N, Devevey G, Yannic G, Patthey P, Maeder A, Vogel P, Arlettaz R: Host sex and ectoparasite choice: preference for, and higher survival on female hosts. J Anim Ecol 2007, 76:703-710.

25. Lourenco S, Palmeirim JM: Which factors regulate the reproduction of ectoparasites of temperate-zone cave-dwelling bats? Parasitol Res 2008, 104:127-134.

26. Lourenco S, Palmeirim JM: Can mite parasitism affect the condition of bat hosts? Implications for the social structure of colonial bats. J Zool 2007, 273:161-168.

27. Giorgi MS, Arlettaz R, Christe P, Vogel P: The energetic grooming costs imposed by a parasitic mite (Spinturnix myoti) upon its bat host (Myotis myotis). Proc R Soc Lond B Biol Sci 2001, 268(1480):2071-2075.

28. Christe $P$, Arlettaz R, Vogel P: Variation in intensity of a parasitic mite (Spinturnix myoti) in relation to the reproductive cycle and immunocompetence of its bat host (Myotis myotis). Ecol Lett 2000, 3:207-212.

29. Reckardt K, Kerth G: Does the mode of transmission between hosts affect the host choice strategies of parasites? Implications from a field study on bat fly and wing mite infestation of Bechstein's bats. Oikos 2009, 118:183-190.

30. Christe P, Giorgi MS, Vogel P, Arlettaz R: Differential species-specific ectoparasitic mite intensities in two intimately coexisting sibling bat species: resource-mediated host attractiveness or parasite specialization? J Anim Ecol 2003, 72:866-872.

31. Castella V, Ruedi M, Excoffier L: Contrasted patterns of mitochondrial and nuclear structure among nursery colonies of the bat Myotis myotis. J Evol Biol 2001, 14(5):708-720.

32. Kerth G, Safi K, Koenig B: Mean colony relatedness is a poor predictor of colony structure and female philopatry in the communally breeding Bechstein's bat (Myotis bechsteinii). Behav Ecol Sociobiol 2002, 52(3):203-210.

33. Sambrook JE, Fritsch F, Manitatis T: Molecular cloning: a laboratory manual. 2nd edition. New York: Cold Spring Harbor Laboratory Press; 1989.

34. Worthington Wilmer J, Barratt E: A non-lethal method of tissue sampling for genetic studies of Chiropterans. Bat Res News 1996, 37(1):1-3.

35. Simons C, Frati F, Beckenbach A, Crespi B, Liu H, Floors P: Evolution, weighting, and phylogenetic utility of mitochondrial gene sequences and a compilation of conserved polymerase chain reaction primers. Ann Entomol Soc Am 1994, 87(6):651-701.
36. van Schaik J, Bruyndonckx N, Kerth G, Christe P: Isolation and characterisation of microsatellite loci for two species of Spinturnicid bat wing mites (Spinturnix myoti and Spinturnix bechsteini). Acarologia 2011, 51(1):127-131.

37. Excoffier L, Laval G, Schneider S: Arlequin ver. 3.0: An integrated software package for population genetics data analysis. Evol Bioinformatics Online 2005, 1:47-50

38. Clement M, Posada D, Crandall KA: TCS: a computer program to estimate gene genealogies. Mol Ecol 2000, 9(10):1657-1659.

39. Goudet J: FSTAT 2.9.3: a program to estimate and test gene diversities and fixation indices (updated from Goudet 1995). Switzerland: Lausanne; 2002.

40. van Oosterhout C, Hutchinson WF, Wills DPM, Shipley P: Microchecker: Software for identifying and correcting genotyping errors in microsatellite data. Mol Ecol 2004, 4:535-538.

41. Rousset F: GENEPOP ' 007: a complete re-implementation of the GENEPOP software for Windows and Linux. Mol Ecol Resour 2008, 8(1):103-106.

42. Peakall R, Smouse PE: GENALEX 6: genetic analysis in Excel. Population genetic software for teaching and research. Mol Ecol 2006, 6(1):288-295.

43. Excoffier $L$, Lischer HEL: Arlequin suite ver 3.5: a new series of programs to perform population genetics analyses under Linux and Windows. Mol Ecol Resour 2010, 10(3):564-567.

44. Meirmans PG, Van Tienderen PH: GENOTYPE and GENODIVE: two programs for the analysis of genetic diversity of asexual organisms. Mol Ecol 2004, 4(4):792-794.

45. Rousset F: Genetic differentiation and estimation of gene flow from F-statistics under isolation by distance. Genetics 1997, 145(4):1219-1228.

46. Pritchard JK, Stephens M, Donnelly P: Inference of population structure using multilocus genotype data. Genetics 2000, 155:945-959.

47. Evanno G, Regnaut S, Goudet J: Detecting the number of clusters of individuals using the software STRUCTURE: a simulation study. Mol Ecol 2005, 14(8):2611-2620.

48. R Development Core Team: $R$ : A language and environment for statisical computing. 2151st edition. Vienna, Austria: R Foundation for Statisical Computing; 2012.

49. Castella V, Ruedi M, Excoffier L, Ibanez C, Arlettaz R, Hausser J: Is the Gibraltar Strait a barrier to gene flow for the bat Myotis myotis (Chiroptera : Vespertilionidae)? Mol Ecol 2000, 9(11):1761-1772.

50. Leo N, Hughes J, Yang X, Poudel S, Brogdon W, Barker S: The head and body lice of humans are genetically distinct (Insecta: Phthiraptera, Pediculidae): evidence from double infestations. Heredity 2005, 95(1):34-40.

51. Price PW: General concepts on evolutionary biology of parasites. Evolution 1977, 31(2):405-420.

52. Kerth G, Mayer F, Konig B: Mitochondrial DNA (mtDNA) reveals that female Bechstein's bats live in closed societies. Mol Ecol 2000, 9(6):793-800.

53. Kerth G, Van Schaik J: Causes and consequences of living in closed societies: lessons from a long-term socio-genetic study on Bechstein's bats. Mol Ecol 2012, 21(3):633-646.

54. Reckardt K, Kerth G: Roost selection and roost switching of female Bechstein's bats (Myotis bechsteinii) as a strategy of parasite avoidance. Oecologia 2007, 154(3):581-588.

55. Caillaud D, Craft ME, Meyers LA: Epidemiological effects of group size variation in social species. J R Soc Promot Interface 2013, 10(83):20130206,

\section{doi:10.1186/1471-2148-14-18}

Cite this article as: van Schaik et al.: The effect of host social system on parasite population genetic structure: comparative population genetics of two ectoparasitic mites and their bat hosts. BMC Evolutionary Biology 2014 14:18. 